\title{
Awareness on the Mental Health Law of Registered Social Workers in Negros Occidental
}

\author{
Adrian L. Patricio ${ }^{1}$ and Richelle H. Verdeprado ${ }^{2}$ \\ ${ }^{1}$ Cadiz District Hospital, Cadiz City, Negros Occidental, Philippines \\ ${ }^{2}$ University of Negros Occidental-Recoletos, Bacolod City, Philippines
}

\begin{tabular}{l} 
Article history \\
Submitted: 23 October 2020 \\
Revised: 5 November 2020 \\
Accepted: 16 November 2020 \\
\hline Keywords \\
Social Work \\
Mental Health Law \\
Awareness \\
Registered Social Workers \\
Descriptive-Comparative \\
Negros Occidental
\end{tabular}

\section{Article history}

Submitted: 23 October 2020

Revised: 5 November 2020

Accepted: 16 November 2020
Introduction. Mental health is the condition of an individual's well-being. Mentally healthy individuals realize their abilities, cope effectively with the everyday stresses encountered in life, show resilience during extreme events in life, perform efficiently, and participate in the community's development. The global concern of mental health issues is enormous, under-appreciated, and mostly not fulfilled. Hence, the paper assessed the awareness on the Mental Health Law of the registered social workers in Negros Occidental in the areas of general provisions, psychiatric, neurologic, and psychosocial services. It also explored social workers' mental health services in educational institutions, communities, hospitals, government agencies, and non-governmental organizations.

Methods. Descriptive and comparative research approaches were used to assess and compare the awareness on the Mental Health Law of registered social workers in Negros Occidental in the areas of general provisions, psychiatric, neurologic, and psychosocial services as well as to evaluate the mental health services rendered by social workers in the educational institutions, community, hospitals, government agencies, and non-governmental organizations. Using stratified random sampling, 160 registered social workers in Negros Occidental were selected to participate in the study. The data were gathered using the researcher-made instrument validated by five experts in social work and psychology. The said instrument was also subjected to reliability testing. Mean, Standard Deviation, frequency count, percentage distribution, Mann Whitey U test, and Kruskal-Wallis $\mathrm{H}$ test were used to analyze the data..

Results. The findings of the study revealed that the registered social workers in Negros Occidental, when they are taken as a whole and grouped according to age, settings, length of service, and educational attainment, are very aware of Mental Health Law in the areas of psychiatric, neurologic, and psychosocial services. This study has shown that social workers in educational institutions, communities, hospitals, government agencies, and non-governmental organizations provide mental health services to their beneficiaries and clients. There is no significant difference in the awareness on the Mental Health Law of registered social workers in Negros Occidental when grouped according to age, settings, and length of service. Meanwhile, there is a significant difference in the awareness on the Mental Health Law of registered social workers in Negros Occidental when grouped according to educational attainment.

Conclusion. The level of mental health law awareness of registered social workers in Negros Occidental is proved to be very high. It can be concluded that age, length of service, and work settings, which exposed no significant difference, are not major factors in assessing the social workers' awareness of the said law. Moreover, it can be inferred that the more educated the worker is, his/her awareness on matters such as mental health and the mental health law is relatively advanced compared to those who did not pursue further studies. Hence, this study's results revealing a very high level of awareness of registered social workers on the mental health law gives assurance and affirmation to every Filipino that mental health services and professionals in our country, particularly the social workers, are vastly improving and developing. A very high level of awareness of mental health law is an essential attribute that a registered social worker must possess to provide competent and comprehensive social welfare programs and services actively and consistently to their clientele. Mental Health Law was just signed two years ago. With high awareness of mental health professionals, 
it can be expected that the law will surely have positive impacts and contributions in the promotion and protection of every Filipino's mental health.

Practical Value of the Paper. The study significantly contributes to the few existing literature on the awareness of the Mental Health Law of Registered Social Workers. The findings of this study will be beneficial to registered social workers of the Province of Negros Occidental in terms of enhancing the quality of mental health services that they offer to their clients. The research-based information will also help them evaluate their awareness of the Philippine Mental Health Law. Likewise, this study will provide future researchers with information to work on areas that have not been tackled in this study, such as the mental health law awareness of other professionals and the country's responsiveness to mental health services.

\section{References}

Abdullah, T. \& Brown, L. (2011). Mental illness stigma and ethnocultural beliefs, values, and norms: An integrative interview. Clinical Psychology Review, 31, 934-948. doi: 10.1016/j.cpr.2011.05.003

Allen, J., Balfour, R., Bell, R. \& Marmot, M. (2014). Social determinants of mental health. Int Rev Psychiatry. Aug; 26(4):392-407. doi:10.3109/09540261.2014.928270.

Baxter, A.J., Scott, K.M., Ferrari, A.J., Norman, R.E., Vos, T. \& Whiteford, H.A. (2014). Challenging the myth of an "epidemic" of common mental disorders: trends in the global prevalence of anxiety and depression between 1990 and 2010. Depression \& Anxiety. 31:506-16. doi: 10.1002/da.22230.

Bourassa, J. (2010). Psychosocial interventions and mass populations: A social work perspective. Sage Publications: Los Angeles, London, New Delhi, Singapore, and Washington DC. doi:10.1177/0020872809342646

Cabaniss, R. (2014). Using Transformative Learning Theory to Impact Patient Care. J Nurs Care 4:223. Retrieved from https://www.hilarispublisher.com/open-access/using-transformative-learning-theory-to-impact-patientcare-2167-1168.1000223.pdf

Conde, B. (2004). Philippines Mental Health Country Profile. International Review of Psychiatry. Retrieved from https://www.tandfonline.com/doi/abs/10.1080/095402603100016

Ines, J. (2019). Filipino College Students' Mental Health Literacy. De La Salle University, Manila, Philippines. Retrieved from https://www.researchgate.net/publication/333917424_Filipino_College_Students' Mental_Health_Literacy

Jorm, A.F., Nakane, Y., \& Christensen, H. (2005). Public beliefs about treatment and outcome of mental disorders: a comparison of Australia and Japan. BMC Med, 3, 12. doi:10.1186/1741-7015-3-12

Lally, J., Samaniego, R. M., \& Tully, J. (2019). Mental health legislation in the Philippines: Philippine Mental Health Act. BJPsych International, 16(3), 65-67. doi:10.1192/bji.2018.33

Samaniego, R.M. (2017). The Evolution of psychiatry and mental health in the Philippines. Taiwanese Journal of Psychiatry, 31, 101-14. Retrieved from http://www.sop.org.tw/sop_journal/Upload_files/31_2/001.pdf

\section{Correspondence:}

Adrian L. Patricio [Patricioadrian18@gmail.com]

https://orcid.org/0000-0001-7780-6692 